\title{
Increasing the reproductive function of boars by introducing phosphatide concentrate into their diet
}

\author{
Alexander Narizhny ${ }^{1, *}$, Abdulaziz Jamaldinov ${ }^{1}$, Grigorii Pokhodnya ${ }^{2}$, Yriy Breslavetz ${ }^{2}$, and \\ Pavel Breslavetz ${ }^{2}$ \\ ${ }^{1}$ Federal Scientific Center of Animal Husbandry-VIZ named after Academician L. K. Ernst, Russia \\ ${ }^{2}$ Belgorod State Agricultural Univerisity named after V. Gorin, pos. Mayskiy, Russia
}

\begin{abstract}
As a result of a number of experiments and studies, it was found that the introduction of phosphatide concentrate in addition to the main diet of boars in the amount of $1.0 ; 2.0 ; 3.0 \%$ allows to increase the manifestation of sexual reflexes. Also, the inclusion of this concentrate increases both quantitative and qualitative indicators of the sperm of experimental boars, which in the experimental groups allows increasing the number of piglets at birth by $7.9 ; 18.9 ; 19.7 \%$, respectively, while the cost of obtaining them is reduced by $7.3 ; 16.0 ; 16.5 \%$, respectively, compared with the control group.
\end{abstract}

\section{Introduction}

The productive qualities and safety of piglets directly depend on the usefulness of feeding, which is characterized by the necessary amount of useful biologically active substances $[1$, $5,6,8,9,10,22]$.

Such substances include phospholipids, especially lecithin, due to the fact that the lack of lecithin negatively affects the formation of the fatty acid composition, reduces the quantity and quality of total liver lipids, and also leads to a decrease in multiple births with an increase in non-viable piglets. In addition, the lack of lecithin accelerates the processes associated with lipid peroxidation in the animal body $[4,9,11,12,15]$.

Scientists have recently studied new properties of previously known basic phospholipids. Thus, it was found that the use of drugs in people with essential phospholipids in their composition not only improves the functional state of the liver, but also leads to an improvement in spermatogenesis, especially with low mobility and a large number of pathological forms of spermatozoa $[7,18,19]$. Phosphatidylcholine is the main phospholipid. As a result of the research, it was found that in addition, he takes part in the fertilization process. During the movement to the egg, the lipid structure of the sperm cell membrane undergoes significant sequential changes, in particular, the process of increasing the ability to fertilize and the phenomenon of activation or acrosomal reaction.

\footnotetext{
${ }^{*}$ Corresponding author: narighniy@mail.ru
} 
Phosphatide concentrate is one of the main sources of phospholipids, which is an additional product in the production of unrefined sunflower oil (FUS).

It is also a product with a high fat content, which consists of phosphates, oil and impurities of a protein nature. It contains a whole complex of unsaturated fatty acids, thiamine, pantothenic acid, lecithin, pyridoxine, riboflavin, in addition, vitamins and trace elements are present $[2,3,16,17,20,21]$.

It is important to note the following-that phosphatide concentrates contain $15.0 \%$ of the active substance phosphatidylcholine.

Studies by many scientists have shown a positive effect of using phosphatide concentrate on increasing the productivity and overall resistance of pigs, as well as on the productivity of broilers $[7,8,10,13,14]$.

In the conducted experiments, we studied the feeding of phosphatide concentrate (FUZ) on the sperm and blood parameters of boars, as well as on their reproductive qualities when various doses of FUZ were included in the diet.

\section{Material and methods of research}

Scientific and production experiments to study the effect of feeding phospholipid concentrate on the reproductive qualities of boars of the Landrace breed were carried out on the basis of a specialized pig breeding enterprise, namely the SPC "Gorin Collective Farm" of the Belgorod region.

To conduct research on the principle of analogues, 4 groups of boars aged 2.5-3.0 years of the Landrace breed were selected, 3 animals in each group. The conditions of keeping the experimental animals were made the same, and the feeding conditions were different. During the entire period of the experiment, the boars of the first control group were fed 3.5 $\mathrm{kg}$ of mixed feed SK-1 per 1 head per day, and the boars of the second, third, and fourth experimental groups were fed $1.0 ; 2.0 ; 3.0 \%$ phospholipid concentrate in addition to the main diet. After 40 days of feeding phospholipid concentrate to boars, the manifestation of sexual reflexes in them, as well as quantitative and qualitative blood parameters and the effectiveness of artificial insemination of sows with the sperm of experimental boars were studied.

\section{Research results}

When studying the manifestation of the sexual reflex in boars, depending on feeding them phosphatide concentrate, it was proved that the total time of sexual reflexes in the experimental groups (2-4 groups) decreased by $11.0-15.0 \%$ compared to the control group. However, it should be noted that in the boars of the experimental groups, the approach reflex decreased by an average of 4.7 times, the copulation reflex decreased by 2.8 times, and the ejaculation reflex increased by $47.0 \%$ compared to the control group.

The effect of feeding phosphatide concentrate to boars on the main indicators of their productivity - sperm production is presented in Table 1 .

Table 1. Indicators of boar sperm production depending on feeding them phosphatide concentrate

\begin{tabular}{|l|c|c|c|c|}
\hline \multirow{2}{*}{\multicolumn{2}{|c|}{ Indicators }} & \multicolumn{3}{|c|}{ Experimental groups } \\
\cline { 2 - 5 } & 1st control & $\begin{array}{c}\text { 2nd } \\
\text { experienced }\end{array}$ & $\begin{array}{c}\text { 3rd } \\
\text { experienced }\end{array}$ & $\begin{array}{c}4 \text { th } \\
\text { experienced }\end{array}$ \\
\hline Sperm volume, $\mathrm{ml}$ & $238.0 \pm 2.1$ & $248.0 \pm 1.1$ & $282.0 \pm 3.0$ & $288.0 \pm 4.1$ \\
\hline
\end{tabular}




\begin{tabular}{|l|c|c|c|c|}
\hline $\begin{array}{l}\text { The concentration of } \\
\text { sperms, million/ml }\end{array}$ & $234.0 \pm 2.0$ & $242.0 \pm 3.0$ & $252.0 \pm 5.0$ & $250.0 \pm 4.0$ \\
\hline $\begin{array}{l}\text { The total number of sperms } \\
\text { in the ejaculate, billion }\end{array}$ & $55.6 \pm 0.8$ & $60.0 \pm 1.2$ & $71.0 \pm 2.0$ & $72.0 \pm 1.8$ \\
\hline Sperm motility, score & 8.1 & 8.2 & 8.4 & 8.4 \\
\hline $\begin{array}{l}\text { Resistance of sperms, conl. } \\
\text { units }\end{array}$ & $1010.0 \pm 45$ & $1520.0 \pm 60$ & $1980.0 \pm 92$ & $1985.0 \pm 90$ \\
\hline $\begin{array}{l}\text { The survivability of sperms } \\
\text { outside the body, hour. }\end{array}$ & $78.0 \pm 0.8$ & $84.0 \pm 0.9$ & $96.0 \pm 0.6$ & $96.0 \pm 0.7$ \\
\hline Safety of acrosomes, \% & 91.0 & 95.0 & 96.0 & 97.0 \\
\hline
\end{tabular}

Analyzing the data presented in Table 1, it can be noted that the inclusion of phosphatide concentrate in the diet of boars had a positive effect on the sperm production of boars of the experimental group. It was found that when fed in addition to the main diet in an amount of $1.0 ; 2.0 ; 3.0 \%$ of phosphatide concentrate to boars, it led to an increase, respectively, by $4.2 ; 18.4 ; 21.0 \%$ of the sperm volume; by $3.4 ; 7.6 ; 6.8 \%$ of the sperm concentration in $1 \mathrm{ml}$ of sperm, by $7.9 ; 27.6 ; 29.4 \%$ of the total number of sperm in the ejaculate, by $1.2 ; 3.7 ; 3.7 \%$ of the sperm motility, by $50.4 ; 96.0 ; 96.5 \%$ of resistance sperms, by $7.6 ; 23.0 ; 23.0 \%$ of the experience of sperms outside the body, in comparison with the first control group. In addition, the safety of acrosomes in the experimental groups (2-4 groups) increased by $4.34,5.4 ; 6.5 \%$, respectively, in comparison with the control group.

Based on these data, it can be assumed that the inclusion of phosphatide concentrate in the feeding of boars helps to improve the biological usefulness of spermatozoa, but this hypothesis should be confirmed by the effectiveness of insemination of sows with the sperm production of experimental boars. In accordance with this, after establishing the quantitative and qualitative indicators of sperm, we performed artificial insemination of sows with the sperm of boars from the experimental group.

The effectiveness of artificial insemination of sows is presented in Table 2.

Table 2. The effectiveness of artificial insemination of sows with the sperm of experimental boars, depending on feeding them phosphatide concentrate.

\begin{tabular}{|c|c|c|c|c|c|c|c|}
\hline \multirow{2}{*}{ 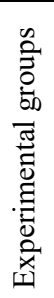 } & \multirow{2}{*}{$\begin{array}{l}\text { The amount of } \\
\text { phosphatide } \\
\text { concentrate in } \\
\text { the diets of } \\
\text { boars, } \%\end{array}$} & \multirow{2}{*}{$\begin{array}{c}\text { Number of } \\
\text { inseminated } \\
\text { x sows, } \\
\text { head }\end{array}$} & \multicolumn{2}{|c|}{$\begin{array}{l}\text { Of them } \\
\text { farrowed }\end{array}$} & \multicolumn{2}{|c|}{$\begin{array}{l}\text { Received piglets, head } \\
\text { (animals) }\end{array}$} & \multirow[b]{2}{*}{ 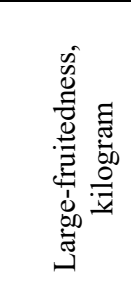 } \\
\hline & & & number & $\%$ & $\begin{array}{l}\text { in } \\
\text { total }\end{array}$ & $\begin{array}{c}\text { for } 1 \\
\text { farrowing }\end{array}$ & \\
\hline 1 & 0 & 30 & 25 & 83.3 & 253 & $10.12 \pm 0.02$ & $1.28 \pm 0.01$ \\
\hline 2 & 1.0 & 30 & 26 & 86.6 & 273 & $10.50 \pm 0.03$ & $1.27 \pm 0.01$ \\
\hline 3 & 2.0 & 30 & 27 & 90.0 & 301 & $11.14 \pm 0.04$ & $1.26 \pm 0.01$ \\
\hline 4 & 3.0 & 30 & 27 & 90.0 & 303 & $11.22 \pm 0.02$ & $1.25 \pm 0.01$ \\
\hline
\end{tabular}

Table 2 shows that the inclusion of phosphatide concentrate in the diets of boars has a positive effect not only on the sperm production of boars, but also increases the effectiveness of artificial insemination of sows. As we can see, the fertilization rate of sows in the experimental groups (2-4 groups) also increased by $3.3 ; 6.7 ; 6.7 \%$, respectively. In turn, multiple births increased by $3.7 ; 10.0 ; 10.8 \%$, respectively, which led to an increase in 
the number of piglets received at birth by $7.9 ; 18.9 ; 19.7 \%$, respectively, in comparison with the first control group in the experimental groups. It should be noted that we did not establish a significant difference between all experimental groups in terms of the weight of piglets at birth (large-fruited).

Based on the conducted studies, we calculated the economic efficiency of feeding phosphatide concentrate to boars (Table 3).

Table 3. The efficiency of using phosphatide concentrate in the diets of boars

\begin{tabular}{|l|c|c|c|c|}
\hline \multirow{2}{*}{ Indicators } & \multicolumn{3}{|c|}{ The amount of phosphatide concentrate in the diets of boars, $\%$} \\
\cline { 2 - 5 } & 0 & 1.0 & 2.0 & 3.0 \\
\hline $\begin{array}{l}\text { Number of boars in the group, } \\
\text { heads }\end{array}$ & 3 & 3 & 3 & 3 \\
\hline Duration of the trial period, days & 30 & 30 & 30 & 30 \\
\hline $\begin{array}{l}\text { Total costs per 1 boar for the } \\
\text { trial period, RUB }\end{array}$ & 1950.00 & 1950.00 & 1950.00 & 1950.00 \\
\hline $\begin{array}{l}\text { The cost of phosphatide } \\
\text { concentrate per 1 boar for the } \\
\text { experimental period }\end{array}$ & 0 & 105.00 & 210.00 & 315.00 \\
\hline $\begin{array}{l}\text { Spermodose was obtained from } \\
1 \text { boar during the experimental } \\
\text { period }\end{array}$ & 90 & 98 & 119 & 120 \\
\hline Cost of 1 spermodose, RUB & 21.66 & 20.96 & 18.15 & 18.87 \\
\hline $\begin{array}{l}\text { The cost of maintaining 30 sows } \\
\text { (gestation period, 115 days), } \\
\text { RUB }\end{array}$ & 172500.00 & 172500.00 & 172500.00 & 172500.00 \\
\hline $\begin{array}{l}\text { The cost of double insemination } \\
\text { of 30 sows, RUB }\end{array}$ & 1299.60 & 1257.60 & 1089.00 & 1132.20 \\
\hline $\begin{array}{l}\text { The total cost of the received } \\
\text { piglets from 30 inseminated } \\
\text { sows, RUB }\end{array}$ & 173799.60 & 173757.60 & 173589.00 & 173632.20 \\
\hline $\begin{array}{l}\text { The number of piglets received } \\
\text { from 30 inseminated sows, head }\end{array}$ & 253 & 273 & 301 & 303 \\
\hline $\begin{array}{l}\text { The cost of 1 piglet at birth, } \\
\text { RUB }\end{array}$ & 686.95 & 636.47 & 576.70 & 573.04 \\
\hline \pm relative to the first group, \% & 0 & -7.3 & -16.0 & -16.5 \\
\hline
\end{tabular}

Analyzing the data in Table 3, we see that from the point of view of economic science, the inclusion of phosphatide concentrate is a justified method So, the additional introduction of this concentrate into the diet of boars in the amount of $1.0 ; 2.0 ; 3.0 \%$ leads to an increase in the number of spermodoses when calculating for the experimental period for 1 boar, by $8.8 ; 32.2 ; 33.3 \%$, respectively, and the cost of 1 spermodose decreases by $3.2 ; 16.2 ; 12.8 \%$, respectively, in comparison with the control group. As is known, quantitative indicators of sperm production cannot be the final criterion for providing recommendations for the use of phosphatide concentrate in the diets of boars. After all, the quantity and quality of the piglets obtained, their cost at birth in the studied variants are key indicators of the efficiency of pig reproduction. Taking into account these circumstances, we can note that as a result of improving the quality indicators of boar sperm in the experimental groups, the fertilization and multiplicity of sows positively changed, which allowed increasing the number of piglets received from 30 inseminated sows by 7.9; 18.9; $19.7 \%$, respectively, and reducing their cost at birth by $7.3 ; 16.0 ; 16.5 \%$, respectively, compared with the control group. 


\section{Conclusion}

In accordance with the above, our studies have shown that feeding phosphatide concentrate in an amount of $1.0 ; 2.0 ; 3.0 \%$ in addition to the main diet to boars is advisable, both from a biological point of view and from the side of economic efficiency. According to the economic efficiency of all the studied options, the optimal one should be considered: feeding of phosphatide concentrate in an amount of $3.0 \%$ in addition to the main diet to producing boars.

\section{References}

1. S.N. Aleynik, G.S. Pokhodnya, A.A. Novikov, S.M. Mirzaev, Fundamentals of breeding business in pig breeding, 181 (Belgorod, Publishing house of LLC CPI "Polyterra", 2020)

2. V.A. Antipov, E.V. Ivanikova, Proceedings of the Kuban state agrarian UNIVERSITY, 1(2), 236-237 (2009)

3. M.S. Harutyunyan, E.P. Korneva, Phospholipids vegetable oils, 256 (M. Agropromizdat, 1986)

4. K.G. Gurevich, Clinical pharmacodynamics 1, 1-5 (2004)

5. V.Ya. Gorin, G.S. Pokhodnya, A.A. Fainov, E.G. Fedorchuk, A.N. Ivchenko, T.A. Malakhova, Zootechnia 5, 24-26 (2014)

6. V.J. Gorin, G.S. Pokhodnya, A.A. Faenov, E.G. Fedorchuk, T.A. Malakhov's, Husbandry 5, 21-23 (214)

7. L.A. Matyushevsky, V.I. Forest, Effect of feeding sows to piglets resistance, Problems of pathology of metabolism in the modern animal husbandry, 103-106 (Voronezh, 1981)

8. K.A. Melnikov, Fat-and-oil industry 2, 20 (2000)

9. A.T. Mysik, G.S. Pokhodnya, D.V. Korobov, Zootechniya 12, 15-18 (2016)

10. A.T. Mysik, G.S. Pokhodnya, E.G. Fedorchuk, Z.I. Getman, Zootechniya 6, 11-12 (2012)

11. A.T. Mysik, G.S. Pokhodnya, T.A. Malakhov, A. Kalinin, N.I. Zhernakova, M.Yu. Skorkina, Husbandry 3, 24-26 (2020)

12. A.T. Mysik, G.S. Pokhodnya, A.V. Kosov, J.P. Breslavets, Husbandry 11, 22-25 (2020)

13. A.T. Mysik, G.S. Pokhodnya, E.G. Fedorchuk, A.N. Ivchenko, N.P. Dudina, Zootechnia 311, 9-11 (2011)

14. N.V. Popova, Efficiency of using full-fat soy and phosphatide concentrate in the diets of broiler chickens, Diss. candidate of Agricultural Sciences, 121 (Kursk, 2003)

15. G.S. Pokhodnya, Pig breeding, 1, 768 (2019)

16. G.S. pokhodnya, M.M. Moroz Husbandry, 6, 31 (2007)

17. G.S. pokhodnya, A.G.T. Yurkin, A.S. Dzhamaldinov, N.I. Maslova, T.A. Malakhov, V.P. Zhabinsky, Pig 6, 25-27 (2016)

18. V.P. Zhabinskaya, N.S. Trubchaninova, G.S. Pokhodnya, D.V. Korobov, V.I. Kotarev, O.E. Tat'yanicheva, N.B. Ordina, International of Advanced Biotechnology and Research (VABR) ISSN 0976-2612, ISSN 2278-599X 10(1), 47-53 (2019) 
19. A.V. Sergienko, G. S. Pokhodnya, O. E. Tatianicheva, Feed additive "Elevit" increases the growth and efficiency of growing piglets, Materials of the international student scientific conference " Gorinsky readings. Science of innovative development of the agroindustrial complex", 50 (P. Maysky, publishing house of the Belgorod State Pedagogical University, 2019)

20. S.A. Skatkov, Pharmatika 7, 26-30 (2001)

21. A.M. Khokhlov, A.S. Smirnova, V.I. Gerasimov, G.S. Pokhodnya, N.I. Zhernakova, P.P. Kornienko, Pig breeding and pork production technology 10, 200-203 (2016)

22. E.G. Fedorchuk, G.S. Pokhodnya, G.I. Gorshkov, A.N. Ivchenko, A.T. Mysik, A.G. Narizhny, Zootechniya 3, 30-31 (2013) 